\begin{tabular}{c} 
Volume and Issues Obtainable at Center for Sustainability Research and Consultancy \\
Journal of Accounting and Finance in Emerging Economies \\
ISSN: 2519-0318 ISSN (E) 2518-8488 \\
Volume 6: Issue 4 December 2020 \\
CSRC \\
Journal homepage: www.publishing.globalcsrc.org/jafee \\
\hline
\end{tabular}

\title{
Home Management Skills in Educated Young Girls in Punjab: A Quantitative Investigation
}

\author{
${ }^{1}$ Dur e Nayab, ${ }^{2}$ Muhammad Jahanzaib, ${ }^{3}$ Rukhsana Bashir \\ ${ }^{1} \mathrm{Ph} . \mathrm{D}$ Scholar, Institute of Education and Research, University of the Punjab, \\ Lahore-Pakistan, durenayab18@yahoo.com
}

Ph.D Scholar, Department of Special Education, University of the Punjab, Lahore-Pakistan, m.zaib92@gmail.com

${ }^{3}$ Assistant Professor, Department of Special Education, University of the Punjab, Lahore - Pakistan, rukhsana.dse@pu.edu.pk

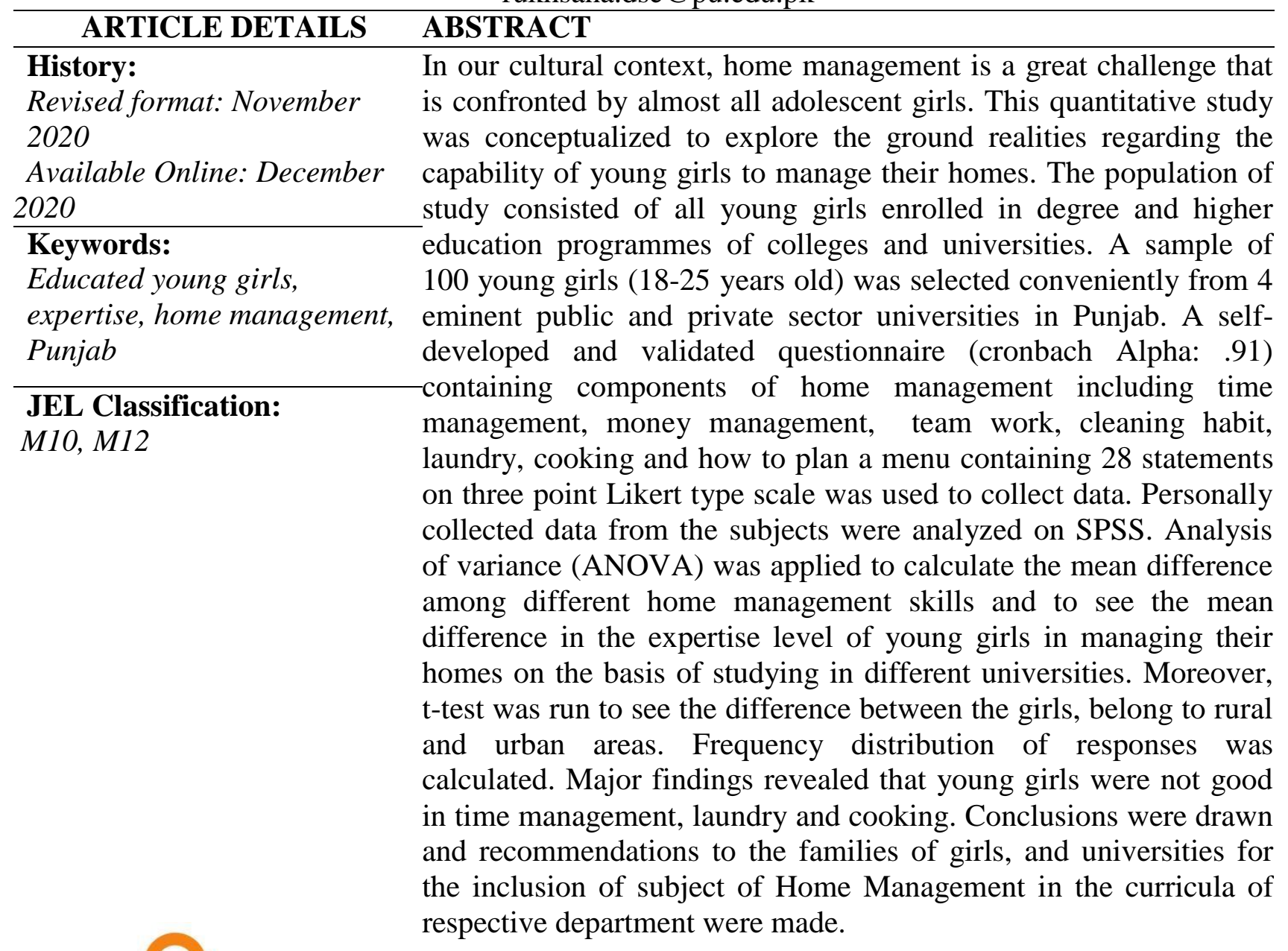

Corresponding author's email address: durenayab18@ yahoo.com

Recommended citation: Nayab, D., Jahanzaib, M. \& Bashir, R. (2020). Home Management Skills in Educated Young Girls in Punjab: A Quantitative Investigation. Journal of Accounting and Finance in Emerging Economies, 6(4), 1151-1157 


\section{Introduction}

The procedure of conserving, looking after and keeping your home is called home management. Home is a place where we relax after a tiring day. Relaxation is essential for the people of all ages.in this sense, home is an assortment of systems and structures. Lastly home management is the actions conceded to protect, guard and develop your home and its structure (Fisher, 2016). Supervising the home accurately is the only way to make it a good livable place because home is the best place where everyone necessitates to live. Home management can also be classified as the effectual use of accessible resources (Anderson \& Anne, 2014). According to Joseph (2017), arranging the home in a proper manner is very useful, small things cannot get worst and it can be solved easily before becoming big problems. If the home is well supervised, bills and taxes paid on time to evade investment and interest charges. People have less stress and therefore they live a longer life. In a well-managed home, things cannot get wasted like eatables, garments medicines and many others. Home management assisted a family, that how to be helpful for one another? Home management permits to work elegantly but not rigidly (Kotzin, 2017).

\subsection{Benefits of Home Management}

According to Anderson and Anne (2014), home Management is an essential component in every family which contributes to the vigor, strength and happiness of the family. Now a days, management is playing an effective role in every field of action. The idea of management contracts with attaining desired goals through planned activity. Home management is actually one of the greatest tasks of the family living, when the family is began(Prospero, 2013). The study of Home administration is personally connected with qualities, models and objectives which offer significance to the lives, considerations, sentiments and encounters of the individuals from the family. These qualities, measures and objectives which are firmly identified with one another, propel the family to decide, to accomplish their coveted objectives. Home administration is fulfilling and a noteworthy help to the homeowner. Begin home consideration with energy and you'll appreciate the advantages (Kotzin, 2017).

\subsection{Significance of Home Management}

According to Joseph (2017), home administration is tied in with enhancing one's home. As the proverb says, "An ounce of Prevention is superior to heaps of Cure". Likewise the house should be kept up to guarantee it is justified regardless of the purchase. Houses are tremendous ventures and legitimate arranging is stressed to guarantee it endures. An all-around oversaw home is all the more fulfilling to live in, spares you cash over the long haul, the embellishments are accessible constantly(Sharon, 2020). Following are some of the factors that assures the excellent management of home.

\subsection{Conserving Home}

Conserving is to make things last. Conserving is the primary line of resistance in the assurance of a home. The machines utilized at home needs usual support to maintain a strategic distance from any breakdowns. House cleaning, painting, supplanting prerequisites in the home guarantees you are safeguarding the nature of your home, decorating your condition. A powerful home administration arrangement is a property holder's most profitable resource (Sharon, 2020).

\subsection{For Protecting Home}

According to Kotzin (2017), security implies protecting or guarding against assault and protecting from threat. Natural dangers like spoil and form are costly to repair, as well as can be undermining to the wellbeing of the occupants. A check in time can avert significant cleaning and limit costs as well. Shielding your home from regular cataclysms like fire, seismic tremor, water flooding. Check for protection inclusion to secure the speculation and family. Check for any harms jumping out at the home by methods for bugs, building harms like breaks. Arranging, sorting out will fend off emergency.

\subsection{For Enhancing Home}

After an immense venture it is fundamental to have a decent upkeep of the home, furniture and 
environment. Arranging the home and the accessible space is a major test. Owning a home can be a test. In any case, dealing with your house is an incredible method to compose assignments in manners that enable you to finish them less demanding and all the more effectively (Balmet, 2014). Your contribution in home upkeep empowers you to take pride of your home and you might be your neighbors envy. Improving your home does not require extra penny, it is a method for standard support. The present homes are more intricate and refined than any time in recent memory. Mortgage holders are likewise busier than any time in recent memory. This is the reason a viable home administration is a boon chance. Dealing with your home appropriately bodes well as far as your property, way of life and esteem (Prospero, 2013).

\subsection{Keeping Up Property Value}

As indicated by Joseph(2017), A home that falls into decay can lose esteem, making it less alluring to potential purchasers. A home administration plan ought to incorporate a timetable for routine support and cleaning for inside and outside of the home and additionally the encompassing property. In case you're not especially helpful or don't have room schedule-wise for upkeep, it tends to be justified regardless of your while over the long haul to employ a jack of all trades or cleaning individual to do a portion of the work for you (Kotzin, 2017).

\subsection{Following Finances}

According to Fisher (2016), home administration likewise ought to incorporate an arrangement to deal with your family unit funds. Set up a month to month spending plan to track costs and take out inefficient spending. Build up an arrangement for dealing with bills when they arrive, for example, setting up a recording framework with a different document for every day of the month and puttng the bill in the document for the day it ought to be paid. Set up a store to cover normal family unit costs, for example, cleaning supplies and groceries.(Palmer, 2019)

\subsection{Showing your Kids}

On the off chance that you have children, getting them associated with home administration can be a decent method to show them the significance of taking care of obligation and dealing with their own family when the time comes(Balmet, 2014). Give them tasks or undertakings to do around the home and include them in the planning procedure by urging them to discover approaches to help trim family costs. Children can likewise give a less expensive wellspring of work than enlisting cleaning or upkeep help.(Palmer, 2019).

\subsection{Objectives of the Study}

Following are the objectives of the study:

1. To find out the level of expertise in educated young girls in managing their homes.

2. To identify the difference between the responses of young educated girls about their level of expertise in managing homes on the basis of their age.

3. To identify the difference between the responses of educated young girls living in rural and urban areas regarding their home management.

4. Give suggestions that how young girls improve their managing skills.

\subsection{Research questions of the Study}

Following are the research questions of the study:

1. What is the level of expertise in educated young girls in managing their homes?

2. Is there any significant difference between young girls regarding their age and their level of expertise in managing homes? 
3. Is there any significant difference between educated young girls living in rural and urban areas regarding their home management?

\section{Methodology}

The study was Quantitative in nature and convenient sampling technique was used for selecting the sample.

\subsection{Population}

According to the information provided by official website of Higher Education Commission, there are 27 public and 24 private sector universities in Punjab. Population of the study consisted of all students enrolled in Bachelors and Master's degree programs of public and private sector universities in Punjab, ranging from 18-25 years of age.

\subsection{Sample}

The sample was selected through simple random sampling technique. At, two public and two private sector universities were selected randomly, 100 students were selected conveniently from each selected university.

\subsection{Instrumentation}

A self-developed and validated questionnaire (cronbach Alpha: .91) containing components of home management including time management, money management, team work, cleaning habit, laundry, cooking and how to plan a menu containing 28 statements on three point Likert type scale was used to collect data. Initially, 35 statements were formulated which were reduced to 28 after getting the questionnaire validated by three educationists and after pilot testing.

\section{Data Analysis}

Data were analyzed by running frequencies. The collected data were tabulated and analyzed as under:

Table 1: Frequency distribution of responses

\begin{tabular}{|c|c|c|c|c|}
\hline $\begin{array}{l}\text { Sr. } \\
\text { no }\end{array}$ & Statements & No & $\begin{array}{ll}\text { To } & \text { some } \\
\text { extent } & \\
\end{array}$ & Yes \\
\hline 1 & You finish every task on time. & 10 & 39 & 51 \\
\hline 2 & You do procrastination. & 36 & 27 & 77 \\
\hline 3 & You avoid procrastination. & 5 & 17 & 78 \\
\hline 4 & $\begin{array}{l}\text { You suffer from your habit of } \\
\text { procrastination. }\end{array}$ & 21 & 21 & 58 \\
\hline 5 & $\begin{array}{l}\text { You have problem in time } \\
\text { management. }\end{array}$ & 22 & 19 & 59 \\
\hline 6 & $\begin{array}{l}\text { You achieve your goals due to good } \\
\text { time management. }\end{array}$ & 42 & 14 & 44 \\
\hline 7 & $\begin{array}{l}\text { You are a looser sometimes as you } \\
\text { cannot manage time. }\end{array}$ & 6 & 14 & 80 \\
\hline 8 & You can properly manage money. & 22 & 10 & 68 \\
\hline 9 & $\begin{array}{l}\text { You do everything within your } \\
\text { means of income. }\end{array}$ & 24 & 4 & 72 \\
\hline 10 & You often borrow money. & 8 & 5 & 87 \\
\hline 11 & You spend more than your earning. & 59 & 10 & 31 \\
\hline 12 & You save money for rainy days. & 54 & 13 & 33 \\
\hline 13 & You collaborate with other people. & 15 & 8 & 77 \\
\hline 14 & $\begin{array}{l}\text { You can manage with people of } \\
\text { different temperaments. }\end{array}$ & 14 & 10 & 76 \\
\hline 15 & $\begin{array}{l}\text { You fully contribute during } \\
\text { involving in team work }\end{array}$ & 15 & 23 & 61 \\
\hline
\end{tabular}




\begin{tabular}{|c|c|c|c|c|}
\hline 16 & $\begin{array}{l}\text { You fully rely on others in team } \\
\text { work. }\end{array}$ & 31 & 20 & 49 \\
\hline 17 & You have cleaning habit. & 36 & 17 & 47 \\
\hline 18 & You create mess while doing a task. & 27 & 7 & 68 \\
\hline 19 & You need assistance in cleaning. & 64 & 7 & 29 \\
\hline 20 & You cook independently. & 47 & 11 & 42 \\
\hline 21 & You need assistance in cooking. & 34 & 21 & 45 \\
\hline 22 & You cannot cook. & 39 & 23 & 38 \\
\hline 23 & You can plan menu independently. & 49 & 12 & 39 \\
\hline 24 & You rely on others to plan a menu. & 23 & 24 & 53 \\
\hline 25 & You do not plan a menu. & 30 & 25 & 45 \\
\hline 26 & You are a good time manager. & 22 & 19 & 59 \\
\hline 27 & $\begin{array}{l}\text { You have problem in time } \\
\text { management. }\end{array}$ & 22 & 19 & 59 \\
\hline 28 & $\begin{array}{l}\text { You are very poor in time } \\
\text { management. }\end{array}$ & 9 & 22 & 69 \\
\hline
\end{tabular}

Table 2: Independent Sample t-test to identify the difference between rural and urban educated young girls regarding home management

\begin{tabular}{lllllll}
\hline Area & $N$ & $M$ & $S D$ & $d f$ & $t$-value & Sig \\
\hline Rural & 43 & 34.74 & 4.811 & 98 & 1.23 & .220 \\
Urban & 57 & 35.93 & 4.720 & & & \\
\hline
\end{tabular}

The results of Independent sample $t$-test (Table:2) reflect that there was no significant difference (rural Mean: 34.74; urban Mean: 35.93) in the opinions of educated young girls on the basis of locale (rural \& urban). It reflects that educated young girls belonging to rural and urban areas were having similar views regarding home management skills.

\section{Major Findings}

Major findings of the study are as follows:

1. Almost $51 \%$ of the girls reported that they could finish every task on time.

2. Majority of the girls $(77 \%)$ said that they did procrastination.

3. A large number of girls $(78 \%)$ responded that they tried to avoid procrastination.

4. Almost $58 \%$ of the girls answered that they suffered from the habit of procrastination.

5. Almost $59 \%$ of the girls reported that they have problem in time management.

6. Some of the girls (44\%) responded that they achieved their goals due to good time management.

7. A vast number of girls (80\%) reported that they lost sometimes as they could not manage time.

8. Many of the girls (68\%) replied that they could properly manage money.

9. Most of the girls (72\%) responded that they used to do everything within their means of income.

10. A large number of girls $(87 \%)$ reported that they often borrowed money.

11. Some of the girls $(31 \%)$ reported that they used to spend more than their earning.

12. Few of them $(33 \%)$ responded that they could save money for rainy days.

13. A majority of girls (77\%) answered that they used to collaborate with other people .

14. Many girls (76\%) reported that they could manage with people of different temperaments.

15. Some of the girls (49\%) responded that they fully relied on others in team work. 
16. Some of the girls (47\%) answered that they had cleaning habit.

17. Most of the girls $61 \%$ reported that they fully contributed while doing team work.

18. Almost $68 \%$ of the girls responded that they used to create mess while doing a task in cleaning

19. Some of the girls (29\%) reported that they used to provide assistance in cleaning.

20. Some of the girls (42\%) reported that they could cook independently.

21. Almost (45\%) of the girls responded that they needed assistance in cooking.

22. Some of the girls $(38 \%)$ reported that they could not cook.

23. Few of the girls $(39 \%)$ reported that they could plan menu independently.

24. Almost half of the girls (53\%) answered that they used to rely on others to plan a menu.

25. Some of girls (45\%) responded that they did not plan a menu.

26. Almost $59 \%$ of the girls responded that they were good time managers.

27. Almost half of the $(59 \%)$ of the girls replied that they had a problem in time management.

28. Most of the girls $(69 \%)$ reported that they were poor in time management.

29. Results of the study revealed that there is no significant difference in the opinions of the girls belonging, to rural and urban areas in managing their homes.

30. On the other hand, study also revealed that young girls are good at managing their homes as compared to other girls.

\section{Discussion and Recommendations}

The study was conducted to find out the expertise of educated young girls in home management. The major focus of the study is to explore the home management skills like managing time, money and planning of educated young girls. The results of the study indicates that young girls (18-21) are more competent in managing homes rather than other girls (22-25), but on the other hand they faced some problems in managing time, money, planning, cooking, cleaning and doing team work. According to Sharon (2020), with regards to home management there is a wide range of perspectives in taking care of a home and in addition to the fact that you need to know the essentials in cleaning, home keeping, money however you additionally need to realize how to plan a menu and do laundry. It was also revealed by the study there is no significant difference in between the girls of rural and urban areas regarding home management. The level of expertise was almost same for the girls of rural and urban areas.

The following recommendations are made on the basis of results of this study:

1. The young educated girls should be trained to complete their assigned tasks on time both at home and in their educational institutions.

2. The young educated girls should be taught to save money for hard times.

3. They should be taught to take care of cleanliness while doing work.

4. A sense of trustworthiness should be created in them to make them able to work in groups.

5. As they are not very good at cooking, special courses on cooking should be arranged in their educational institutions.

6. It is recommended that text books of elective subject like Economics must contain chapters and units related to planning and budgeting of homes.

7. Administration of universities should arrange special workshops for young girls as they need to be able how to do the house management.

8. Teachers should be trained to make their students more organized and good managers in universities and in homes as well.

9. Home management should also be included as a subject in the curricula of different departments in universities.

10. Seminars should be arranged for the parents, so that parents can realize that home management is very much important for their girls 


\section{References}

Anderson, J., \& Anne , A.(2014). Essential home management skills to teach your child. Retrieved on $4^{\text {th }}$ April 2018 from https://www.popsugar.com/moms/Teaching-Kids-Life-Skills-27333084.

Balmet, J. (2014). Managing your home...for God's glory. Retrieved on March 24, 2018 from https://youngwifesguide.com/managing-your-home-for-gods-glory/ .

Fisher, J.(2016). What is home management? And How Can I Get Better at It? Retrieved on $2^{\text {nd }}$ April 2018 from http://lifeasmom.com/what-is-home-management/.

Joseph, C.(2017). Importance of home management. Retrieved from sapling.com/8153806/importance-home-management

Kotzin, (2017).The Importance of home management. Retrieved on 22 August,2019 from http://www.homemanagementinfo.com/theimportance-of-home-management/.

Palmer, S.(2019).Importance of home management. Accessed on 15 October, 2019 from https://www.sapling.com/8153806/importance-home-management.

Prospero, T. (2013). Importance of home management. Retrieved on $4^{\text {th }}$ April 2018 from https://prezi.com/fdhmfolxdv3k/importance-of-home-management/.

Sharon.(2020). How to get organized at home. Retrieved from https://howtogetorganizedathome.com/home-management-skills/ on August 2020. 